\title{
Effect of a MAST Exercise Program on Anthropometric Parameters, Physical Fitness, and Serum Lipid Levels in Obese Postmenopausal Women
}

\author{
by \\ Bartosz Trabka ${ }^{1}$, Igor Z. Zubrzycki1, Zbigniew Ossowski1, Olgierd Bojke', \\ Anna Clarke², Magdalena Wiacek ${ }^{1}$ Ewelina Latosik ${ }^{3}$
}

The purpose of this study was to examine an influence of a mixed aerobic and strength training program (MAST) on anthropometry, serum lipid levels, physical performance, and functional fitness in obese postmenopausal women. The MAST sessions were held three times per week, and the exercise program lasted for 10 weeks. The exercise group demonstrated a statistically significant improvement in maximal oxygen uptake, a waist/hip ratio, and strength of the upper and lower body. An increase in LDL-C levels was observed in the control group. A 10-week MAST program encompassing Nordic-walking as an aerobic component, and strength exercises, induces positive changes in functional fitness, HDL-C, LDL-C and a waist/hip ratio in obese postmenopausal women. The observed changes implicate an increase in a health-related quality of life among the women administered to the physical exercise program.

Key words: exercise; postmenopause; physical fitness; obesity; serum lipids, nordic-walking.

\section{Introduction}

Obesity is accompanied by an elevated Body Mass Index (BMI) and adverse lipid profiles. An interplay of these two factors may result in an increase of risk of cardiovascular diseases (Gorodeski, 2002) stemming into a decrease in Health-Related Quality of Life (HRQoL) (Fontaine and Barofsky, 2001). Although, obesity does not influence maximal aerobic capacity (Goran et al., 2000), it may decrease the level of physical fitness (Uthman and Aremu, 2007), and influence HRQoL (Hakkinen et al., 2010).

It has been shown that aerobic and strength exercises have a positive effect not only on levels of BMI and WC (Martins et al., 2010), but also on serum TC (Boyden et al., 1993; Lennon et al., 1983), TG (Kemmler et al., 2004a) and LDL-C levels (Hagner et al., 2009) and may augment a level of functional fitness among osteopenic postmenopausal women (Bravo et al., 1996).

Notwithstanding the plethora of information on correlations between physical exercises and menopause associated changes in physical fitness, functional fitness, serum lipid levels and maximal aerobic capacity, we still do not know what exercise intensity and/or what type of exercises is required to alleviate these detrimental phenomena in obese postmenopausal women.

The purpose of this pilot study was to determine the potential effect of a supervised mixed aerobic (Nordic-walking, NW) and strength training (MAST) program on

1 - Jędrzej Śniadecki Academy of Physical Education and Sport, Gdańsk, Poland.

2 - Department of Microbiology and Biochemistry, University of Fort Hare, Alice, South Africa.

3 - Department of Theory of Sports Training, Academy of Physical Education in Katowice, Poland. 
anthropometry, serum lipids, physical performance expressed in terms of $\mathrm{VO} 2$ max, and functional fitness in postmenopausal obese women.

\section{Material and Methods}

\section{Participants}

We conducted a 10-week randomized controlled trial with a parallel-group design of obese postmenopausal women. The Bioethics Commission of Regional Medical Chamber approved the study protocol, and all the participants gave their written informed consent.

In this study, the following inclusion criteria were employed: (a) postmenopausal female, i.e., the female who had the last period $>12$ months ago, and (b) BMI $\geq 25 \mathrm{~kg} / \mathrm{m}^{2}$ and $\leq 40 \mathrm{~kg} / \mathrm{m}^{2}$. Exclusion criteria were: (a) systolic BP $\geq 140$ $\mathrm{mmHg}$ and/od diastolic BP $\geq 90 \mathrm{mmHg}$, (b) oophorectomy, (c) chemotherapy within six months before screening, (d) coronary artery disease, (e) renal failure, (f) rheumatoid arthritis, (g) pulmonary disease, (h) diabetes mellitus or type II diabetes treated with insulin, (i) myocardial infarction or surgery within six months before screening, (j) smoking of more than two cigarettes per week or consuming more than the equivalent of one glass of wine per day, and (j) inability to obtain approval for participation in the study from a primary-care physician.

All participants were recruited from the students attending a variety of lectures at the University of the Third Age. Of 740 women who agreed for the primary screening only 46 met all the criteria to participate in the study (Figure 1). The control and the intervention groups were randomly allocated through ballot drawing. Such an approach resulted in equal division of subjects into 2 groups comprising 23 subjects each. However, two patients refused to be included in the control group and requested to be included in the intervention group. This resulted in the control group comprising $\mathrm{n}=21$ subjects and intervention group $\mathrm{n}=25$ subjects. Notwithstanding a written agreement to participate in the study two patients from the intervention group were excluded due to personal reasons. Since all the subjects were allocated randomly to the intervention and the control group, we expected some statistical differences between both groups at baseline evaluations.

\section{Measures}

Data Acquisition

The body height in $\mathrm{cm}$ was measured with accuracy of $0.1 \mathrm{~cm}$. The subject was placed during measurement barefoot in the orthostatic position. Body mass in $\mathrm{kg}$ with accuracy of $0.1 \mathrm{~kg}$ was measured for each subject with minimal clothing. The body mass index (BMI) was calculated using the equation: body mass/height ${ }^{2}\left(\mathrm{~kg} / \mathrm{m}^{2}\right)$. Waist circumference (WC) was measured at the midpoint between the iliac crest and the external face of the last rib with accuracy of $0.1 \mathrm{~cm}$. Hip circumference (HC) was measured as the maximal circumference over the buttocks with accuracy of $0.1 \mathrm{~cm}$.

Functional fitness was assessed by a means of the Fullerton battery (Jones and Rikli, 2000). The battery comprised of the following tests: a) chair stand (CST), b) arm curl (CURL), c) chair sit and reach (CSR), and d) back scratch (UBF). The chair stand tests comprised of a number of full stands completed in $30 \mathrm{~s}$. The arm curl employed the number of biceps curls completed in $30 \mathrm{~s}$ using a dumbbell of $2 \mathrm{~kg}$. In the chair sit and reach test, the subject began in a sitting position with legs extended, and then attempted to reach their toes. In the flexibility test, the number of centimeters between the extended fingers, and toes was measured as a score. The back scratch test was performed with one hand reaching over the shoulder and other hand reaching around and up the back. The score was the number of centimeters between the extended fingers of both hands. All the tests were performed between breakfast and lunch in order to assess functional fitness and to avoid skewing of results by daily activities.

$\mathrm{VO}_{2 m a x}$ peak was assessed by open-circuit spirometry using a modified protocol proposed by Ainsworth et al. (1997). In brief, (a) the test was preceded by a 2 min warm-up: walking at the speed of 2-3 km/hr, (b) the subject started walking, without holding onto the handrails during the test, at $4 \mathrm{~km} / \mathrm{hr}$ and $0 \%$ grade. An elevation was increased by $2 \%$ each 2 min stage until volitional fatigue. The test was continued until the subject could not longer continue due to a too great elevation, achieved a respiratoryexchange ratio $>1.0$, a maximal hear rate greater than $\mathrm{HR}=206-0.88^{*}$ age, or other clinical reason for test termination was observed. The heart rate, $\mathrm{BP}$, and rating of perceived exertion using the 
Borg Scale (Borg, 1982) were obtained before the treadmill test, during the last $30 \mathrm{~s}$ of each stage and during a 6 min recovery period. $\mathrm{VO}_{2 \max }$ was measured using a breath-by-breath gas-exchange system (MetaMax 3B, Cortex-Medical, Germany). In this study, oxygen uptake data are expressed as $\mathrm{VO}_{2}$ peak.

Diet

Both the intervention group and the control group were preconditioned for 3 weeks before starting the experiment and the following dietary guidelines through the time of the experiment were employed: (a) no high-glycemic-index food (GI > 75), (b) no high-fat food, (c) no eating after 7 p.m. or three hours before sleep, (d) drinking at least $1.5 \mathrm{l}$ of water per day, (e) eating five times a day, and (f) no drinking of alcohol during the test period. Each subject was asked to cover a total between $120-150 \%$ of the Basal Metabolic Rate $(\mathrm{BMR}) /$ day, based on the provided nutritive value of foods table (Gebhardt et al., 2002). All subjects were asked to make notes of their daily diet during the study period. To satisfy the experimental demands weekly briefings, reminding patients the aims of the study, were executed.

\section{Procedures}

\section{Training Program}

The MAST sessions were held three times a week and the exercise program lasted for 10 weeks. Each exercise session consisted of a $10 \mathrm{~min}$ warm-up, $40 \mathrm{~min}$ of $\mathrm{NW}$ training, $20 \mathrm{~min}$ of strength-training exercises, and $10 \mathrm{~min}$ of a cooldown by stretching.

The target heart rate increased progressively from $50 \%$ up to $80 \%$, at a $10 \%$ increase per 2 weeks, of heart rate reserve by the end of the intervention period.

Target heart rates were obtained using a combination of the HRmax expressed by the following formula: $\mathrm{HR}=206-0.88 \bullet$ (age) (Gulati et al., 2010), and the Karvonen formula [(HR $\max$ $\left.\mathrm{HR}_{\text {rest }}\right) \bullet(0.50$ to 0.80$\left.)\right]+\mathrm{HR}_{\text {rest. }}$ The heart rate was monitored by a Polar S-610 heart-rate monitor (Polar Electro Oy, Finland).

After aerobic training, strength training (ST) was performed. ST exercises employed a subject's own body mass and included squats, heel-raises, sit-ups, and push-ups on knees. Each exercise was performed in three sets, each set comprising the following number of repetitions: squats -15 reps, heel-raises - 30 reps, sit-ups - up to exhaustion, push-ups on knees - 15 reps.

A fasting blood draw was completed to measure blood glucose, total cholesterol, triglycerides, and high and low-density lipoprotein cholesterol. Serum lipid levels were measured immediately on the first and last days of the training program on an empty stomach. LDL-C, HDL-C, triglycerides (TG), and total cholesterol (TC) concentrations were analyzed using the ARCHITECT ci8200 Integrated System, Abbott Diagnostic.

\section{Statistical Analysis}

Normality of samples was tested by means of the Shapiro-Wilk test (Shapiro and Wilk, 1965) and graphically using a histogram and a quantilequantile plot. Changes induced by the training/sedentary period in the specific parameter were analyzed by means of a t-test for repeated measures or the Wilcoxon signed-rank test. Differences between the groups were analyzed using an unpaired t-test or the Wilcoxon rank sum test.

Statistical significance was defined using the $\mathrm{p}$ value of a respective statistical test. The null hypothesis of the specific test was rejected at the statistical significance level of $p<0.05$.

To assess the relative changes in the mean values for a specific parameter, we used the "natural" relative difference, employing natural logarithm, denoted as log percent (L\%) (Tornqvist et al., 1985).

\section{Results}

Because the analyzed data fall into parametric and non-parametric distributions, the basic statistics are represented as the median, first, and third quartile (Table 1).

There are statistically significant differences between the intervention group and the control group in lower-body strength (Training group < Control group), upper-body strength (Training group < Control group), and upper-body flexibility (Training group < Control group) at baseline (Table 1). After the training period, there was a difference between the intervention group and the control group in upper-body strength.

Application of a 10-week MAST program resulted in a statistically significant increase of $\mathrm{VO}_{2 \max }$, equal to $7.06 \mathrm{~L} \%$, WHR equal to $0.45 \mathrm{~L} \%$, lower-body strength $(15.3 \mathrm{~L} \%)$, and upper-body strength $(3.09 \mathrm{~L} \%)$. In the control group, there was 
a statistically significant increase in serum LDL-C levels of $0.72 \mathrm{~L} \%$.

In both groups, there was an improving trend of body mass and the BMI. However, in the group administered to MAST, this trend was three times greater than in the control group. There was also an improving trend in serum lipid profiles in the MAST group, i.e., a decrease in TG and LDL-C levels, and an increase in HDL-C levels.

\section{Discussion}

The 10-week supervised MAST program improved $\mathrm{VO}_{2 \max }$, as well as the upper and lowerbody strength in obese postmenopausal women. Additionally, we observed an improvement in serum TG, HDL-C, and LDL-C levels. Although, there was a significant detrimental increase in WHR, it did not fall into the cardiovascular disease risk bracket. Although, the main limitation of this study was the small sample size rendered by strict inclusion/exclusion criteria, the strength of this study was a fully supervised intervention program comprising outdoor aerobic exercises.

The results were obtained by a moderate amount ( $40 \mathrm{~min})$ of outdoor aerobic training. Although, an earlier study indicates an improvement of $4 \mathrm{~L} \%$ in $\mathrm{VO}_{2 \text { max }}$ after 12-week aerobic NW training comprising three $90 \mathrm{~min}$ sessions (Hagner et al., 2009), application of the MAST program resulted in an improvement of $\sim 7$ L\% after only a 10-week program, comprising $\mathrm{NW}$ as an aerobic component of the training.

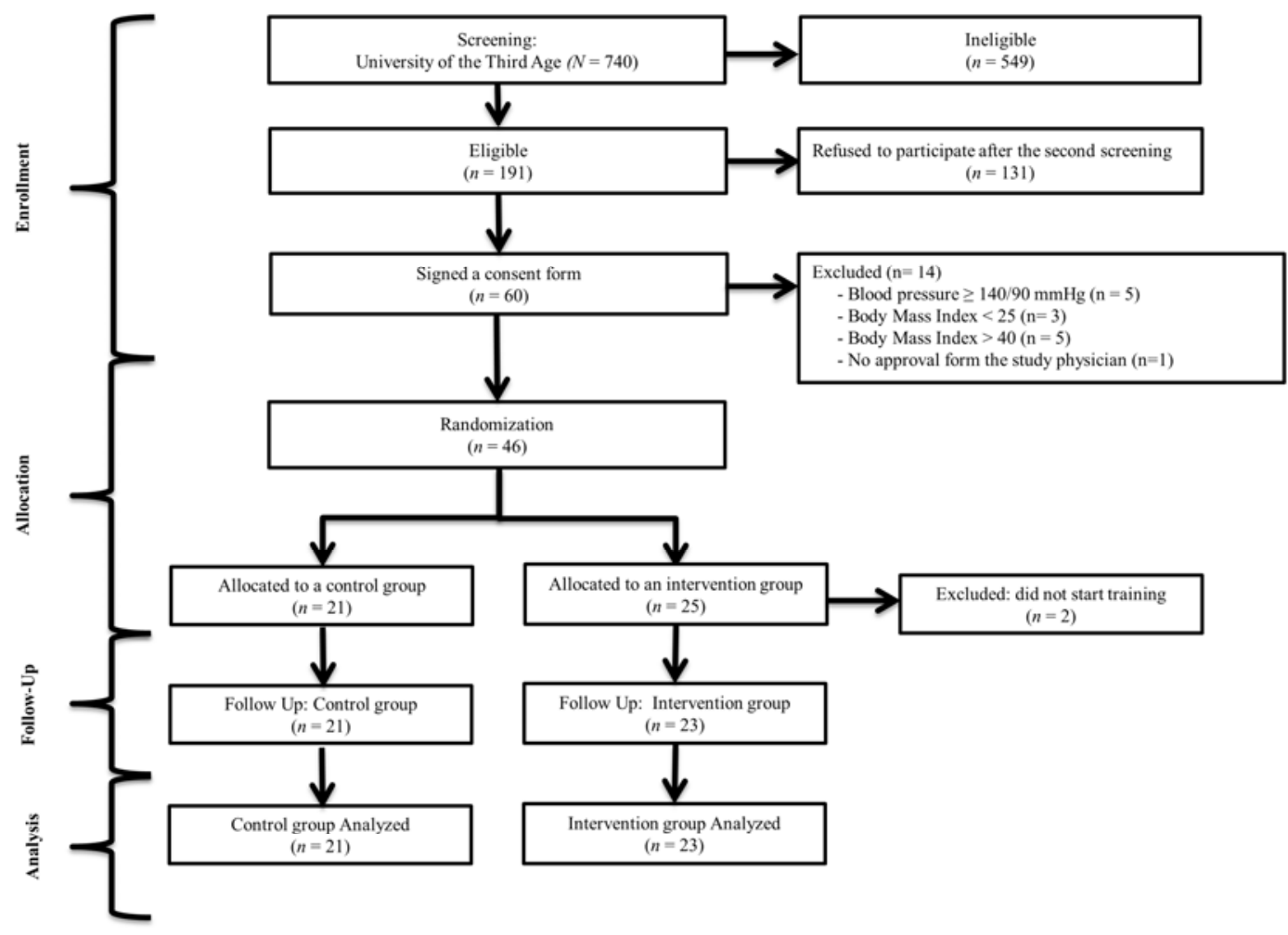

Figure 1

Flow chart of the study arrangement 
Table 1

Differences in anthropometry, serum lipids, physical performance, and functional fitness at baseline and after a 10 week (MAST) aerobic and strength training period in postmenopausal women

\begin{tabular}{|c|c|c|c|c|c|c|c|c|c|c|}
\hline & \multicolumn{3}{|c|}{ Baseline (week 0) } & \multicolumn{3}{|c|}{ Week 8} & \multicolumn{2}{|c|}{$\begin{array}{l}\text { Log } \% \text { of } \\
\text { change }\end{array}$} & \multicolumn{2}{|c|}{$\begin{array}{c}\mathrm{p}< \\
0.05\end{array}$} \\
\hline & $\operatorname{Ex}(n=23)$ & $\mathrm{p}$ & Cont $(n=21)$ & $\operatorname{Ex}(n=23)$ & $\mathrm{p}$ & Cont $(n=21)$ & 爻 & $\overrightarrow{0}$ & 差 & $\overrightarrow{0}$ \\
\hline & $\begin{array}{c}\text { Median } \\
(1 \mathrm{QR}, 3 \mathrm{QR})\end{array}$ & & $\begin{array}{c}\text { Median } \\
(1 \mathrm{QR}, 3 \mathrm{QR})\end{array}$ & $\begin{array}{c}\text { Median } \\
(1 \mathrm{QR}, 3 \mathrm{QR})\end{array}$ & & $\begin{array}{c}\text { Median } \\
(1 \mathrm{QR}, 3 \mathrm{QR})\end{array}$ & & & & \\
\hline \multicolumn{11}{|l|}{ Anthropometry } \\
\hline $\begin{array}{l}\text { Body mass } \\
\quad(\mathrm{kg})\end{array}$ & $\begin{array}{c}83.6 \\
(75.1,91.1)\end{array}$ & & $\begin{array}{c}83.44 \\
(74.9,91.1)\end{array}$ & $\begin{array}{c}81.64 \\
(73.2,90.9)\end{array}$ & & $\begin{array}{c}82.82 \\
(74.2,91.1)\end{array}$ & -1.0 & -0.3 & & \\
\hline BMI $\left(\mathrm{kg} / \mathrm{m}^{2}\right)$ & $\begin{array}{c}31.64 \\
(28.6,34.1)\end{array}$ & & $\begin{array}{c}31.73 \\
(28.5,35.1)\end{array}$ & $\begin{array}{c}30.9 \\
(27.8,33.5)\end{array}$ & & $31.5(28.3,34.2)$ & -1.0 & -0.3 & & \\
\hline $\mathrm{Wc}(\mathrm{cm})$ & $\begin{array}{c}107.75 \\
(101.3,114.9)\end{array}$ & & $\begin{array}{c}109.11 \\
(102.4,115.5)\end{array}$ & $\begin{array}{c}106.79 \\
(100.3,112.2)\end{array}$ & & $\begin{array}{c}109.15 \\
(102.4,115.1)\end{array}$ & -0.3 & 0.0 & & \\
\hline $\mathrm{Hc}(\mathrm{cm})$ & $\begin{array}{c}111.93 \\
(105.1,118.3)\end{array}$ & & $\begin{array}{c}113.65 \\
(106.4,120.3)\end{array}$ & $\begin{array}{c}110.63 \\
(103.6,117.1)\end{array}$ & & $\begin{array}{c}114.56 \\
(107.4,122.1)\end{array}$ & -0.5 & 0.3 & & \\
\hline whr & $\begin{array}{c}0.96 \\
(0.9,1)\end{array}$ & & $\begin{array}{c}0.96 \\
(0.95,0.97)\end{array}$ & $\begin{array}{c}0.97 \\
(0.96,0.98)\end{array}$ & & $0.59(0.58,0.6)$ & 0.4 & -0.4 & $a$ & \\
\hline \multicolumn{11}{|l|}{ Serum lipids } \\
\hline $\mathrm{TC}(\mathrm{mmol} / \mathrm{L})$ & $\begin{array}{c}6.26 \\
(5.6,6.7)\end{array}$ & & $\begin{array}{c}6.08 \\
(5.11,7.00)\end{array}$ & $6.43(5.7,7.2)$ & & $6.03(5.1,7.2)$ & 1.2 & -0.4 & & \\
\hline $\mathrm{TG}(\mathrm{mmol} / \mathrm{L})$ & $1.18(0.9,1.4)$ & & $\begin{array}{c}1.1 \\
(0.71,1.47)\end{array}$ & $1.01(0.7,1.2)$ & & $1.15(0.8,1.6)$ & -6.8 & 1.9 & & \\
\hline $\begin{array}{c}\text { HDL-C } \\
(\mathrm{mmol} / \mathrm{L})\end{array}$ & $1.87(1.6,2.1)$ & & $\begin{array}{c}1.93 \\
(1.58,2.23)\end{array}$ & $2.04(1.8,2.3)$ & & $1.87(1.3,2.2)$ & 3.8 & -1.4 & & \\
\hline $\begin{array}{c}\text { LDL-C } \\
(\mathrm{mmol} / \mathrm{L})\end{array}$ & $4.1(3.4,4.8)$ & & $\begin{array}{c}3.58 \\
(2.65,4.51)\end{array}$ & $\begin{array}{c}3.29 \\
(2.62,3.96)\end{array}$ & & $3.64(2.8,4.5)$ & -1.9 & 0.7 & & $a$ \\
\hline $\begin{array}{c}\text { Physical } \\
\text { performance } \\
\text { Peak } \mathrm{VO}_{2 \max } \\
\text { (ml/kg/min) } \\
\text { Functional } \\
\text { fitness }\end{array}$ & $\begin{array}{c}26.3 \\
(22.2,30.1)\end{array}$ & & $\begin{array}{c}25.5 \\
(22.0,28.6)\end{array}$ & $\begin{array}{c}30.94 \\
(26.6,34.3)\end{array}$ & & $26(23.1,28.5)$ & 7.1 & 0.8 & $a$ & \\
\hline CST (rep/sek) & $0.45(0.2,0.6)$ & $b$ & $0.68(0.4,0.9)$ & $0.64(0.5,0.8)$ & & $0.63(0.4,0.8)$ & 15.3 & -3.3 & $a$ & \\
\hline $\begin{array}{c}\text { CURL } \\
\text { (rep/sek) }\end{array}$ & $0.54(0.5,0.7)$ & $b$ & $0.65(0.4,0.8)$ & $0.73(0.5,0.8)$ & $b$ & $0.6(0.5,0.7)$ & 3.09 & -3.5 & $a$ & \\
\hline $\mathrm{UBF}(\mathrm{cm})$ & $\begin{array}{c}-5.32 \\
(-12.9,2.4)\end{array}$ & $b$ & $\begin{array}{c}-6.32 \\
(-13.0,0.5)\end{array}$ & $\begin{array}{c}-5.14 \\
(-13.0,2.5)\end{array}$ & & $\begin{array}{c}-6.37 \\
(-13.0,0.4)\end{array}$ & -1.49 & 0.3 & & \\
\hline $\operatorname{CSR}(\mathrm{cm})$ & $\begin{array}{c}4.18 \\
(-2.1,10.5) \\
\end{array}$ & & $\begin{array}{c}1.04 \\
(-4.2,6.4)\end{array}$ & $\begin{array}{c}4.36 \\
(-2.0,11.0) \\
\end{array}$ & & $\begin{array}{c}0.99 \\
(-4.1,6.3) \\
\end{array}$ & 1.83 & -2.1 & & \\
\hline
\end{tabular}

$B M I=$ Body Mass Index; Ex = exercise group; Cont = control group; $T C=$ total cholesterol;

$T G=$ triglycerides; $H D L-C=$ high-density cholesterol; $L D L-C=$ low-density cholesterol; $S D=$ standard deviation

$a$ - $p$-value less than 0.05 for differences in means/medians induced by the experiment; $b$ - $p$-value less than 0.05 for differences in means/medians between

the experimental group and control group for the specific period of the experiment.

Contrary to previous results, indicating that aerobic exercises in the form of stationary cycling, at $55 \%$ of each participant's maximal oxygen uptake, result in an acute decrease in TC levels
(Lennon et al., 1983), this study did not show a decrease in the serum TC level after the MAST program. However, the MAST training led to changes in TG levels that were similar to those 
observed in the previous study on postmenopausal women administered to different forms of aerobic exercises (Fahlman et al., 2002; Hagner et al., 2009; Kemmler et al., 2004b).

In this study, we also showed an increase in WHR, which indicated a greater increase in the waist than this in the hip area. Since we did not study the level of fat tissue in the waist and hip areas, we were unable to assess the reasons of this phenomenon. Among possible explanation of this singularity, rendered by an analysis of Table 1 , was a decrease of fat tissue in the hip area.

In the present study we showed that a combination of strength and aerobic training resulted in a significant increase of upper and lower-body strength which in turn may result in improvement of a health-related quality of life (Wiacek et al., 2009). Although, a change in $\mathrm{VO}_{2 \max }$ alone cannot serve as an indicator of a cardiac function in obese women (Lewis et al., 2010) we hypothesized that positive trends in serum lipids, an increase in HDL-C levels and a decrease in LDL-C levels, as well as $\mathrm{VO}_{2 \max }$ may serve as a predictor of an improved cardiovascular function among obese postmenopausal women administered to the MAST program.

\section{Conclusions}

This study measured influence of a 10-week MAST program on a level of physical performance, functional fitness, anthropometry, and serum lipid levels in obese postmenopausal women. It provides insights suggesting that a MAST program, of which an aerobic component includes Nordic-walking, may be used as a means of improvement of HRQL in terms of a positive trend in serum lipid levels, $\mathrm{VO}_{2 \max }$ and body strength.

The results of this study may be further used for planning an intervention program for obese elderly women.

\section{Practical Implications}

- A 10-week MAST program, encompassing NW as an aerobic component, increases upper and lower-body strength in obese postmenopausal women.

- A 10-week MAST program increases physical performance in terms of $\mathrm{VO}_{2 \max }$ in obese postmenopausal women.

- A 10-week MAST program results in positive changes in serum lipid levels in obese postmenopausal women.

\section{Acknowledgements}

The authors gratefully acknowledge the financial support of the grant RSA2 05352 awarded to IZZ

\section{References}

Ainsworth BE, McMurray RG, Veazey SK. Prediction of peak oxygen uptake from submaximal exercise tests in older men and women. Journal of Aging and Physical Activity, 1997; 5(1): 27-38

Borg GAV. Psychophysical Bases of Perceived Exertion. Med Sci Sports Exerc, 1982; 14(5): 377-381

Boyden TW, Pamenter RW, Going SB, Lohman TG, Hall MC, Houtkooper LB, Bunt JC, Ritenbaugh C, and Aickin M. Resistance Exercise Training Is Associated with Decreases in Serum Low-DensityLipoprotein Cholesterol Levels in Premenopausal Women. Archives of Internal Medicine, 1993; 153(1): 97-100

Bravo G, Gauthier P, Roy PM, Payette H, Gaulin P, Harvey M, Peloquin L, Dubois MF. Impact of a 12-month exercise program on the physical and psychological health of osteopenic women. Journal of the American Geriatrics Society, 1996; 44(7): 756-762

Fahlman MM, Boardley D, Lambert CP, Flynn MG. Effects of endurance training and resistance training on plasma lipoprotein profiles in elderly women. J Gerontol A Biol Sci Med Sci, 2002; 57(2): B54-60

Fontaine KR, Barofsky I. Obesity and health-related quality of life. Obes Rev, 2001; 2(3): 173-182

Gebhardt SE, Thomas RG, United States. Agricultural Research Service. Nutritive value of foods (Rev. October 2002. ed.). Washington, DC: U.S. Dept. of Agriculture For sale by the Supt. of Docs., U.S. G.P.O.; 2002 
Goran M, Fields DA, Hunter GR, Herd SL, Weinsier RL. Total body fat does not influence maximal aerobic capacity. Int J Obes Relat Metab Disord, 2000; 24(7): 841-848

Gorodeski GI. Update on cardiovascular disease in post-menopausal women. Best Pract Res Clin Obstet Gynaecol, 2002; 16(3): 329-355

Gulati M, Shaw LJ, Thisted RA, Black HR, Bairey Merz CN, Arnsdorf MF. Heart rate response to exercise stress testing in asymptomatic women: the st. James women take heart project. Circulation, 2010; 122(2): 130-137

Hagner W, Hagner-Derengowska M, Wiacek M, Zubrzycki IZ. Changes in level of VO2max, blood lipids, and waist circumference in the response to moderate endurance training as a function of ovarian aging. Menopause, 2009; 16(5): 1009-1013

Hakkinen A, Rinne M, Vasankari T, Santtila M, Hakkinen K, Kyrolainen H. Association of physical fitness with health-related quality of life in Finnish young men. Health Qual Life Outcomes, 2010; 8: 15

Jones CJ, Rikli RE. The application of Fullerton's Functional Fitness Test for older adults in a group setting. Science E Sports, 2000; 15(4): 194-197

Kemmler W, Lauber D, Weineck J, Hensen J, Kalender W, Engelke K. Benefits of 2 years of intense exercise on bone density, physical fitness, and blood lipids in early postmenopausal osteopenic women: results of the Erlangen Fitness Osteoporosis Prevention Study (EFOPS). Archives of Internal Medicine, 2004a; 164(10): 1084-1091

Kemmler W, Lauber D, Weineck J, Hensen J, Kalender W, Engelke K. Benefits of 2 years of intense exercise on bone density, physical fitness, and blood lipids in early postmenopausal osteopenic women: results of the Erlangen Fitness Osteoporosis Prevention Study (EFOPS). Arch Intern Med, 2004b; 164(10): 10841091

Lennon DL, Stratman FW, Shrago E, Nagle FJ, Hanson PG, Madden M, Spennetta T. Total cholesterol and HDL-cholesterol changes during acute, moderate-intensity exercise in men and women. Metabolism, 1983; 32(3): 244-249

Lewis N, Barker D, O'Kane M, Sharp L, Clement R, Pollard S, Tan LB. Vo2max/kg Is Unreliable as an Indicator of Cardiac Function in Obese Patients. Heart, 2010; 96: A38-A39

Martins RA, Verissimo MT, Coelho e Silva MJ, Cumming SP, Teixeira AM. Effects of aerobic and strengthbased training on metabolic health indicators in older adults. Lipids Health Dis, 2010; 9: 76

Shapiro SS, Wilk MB. An Analysis of Variance Test for Normality (Complete Samples). Biometrika, 1965; 52(3/4): 591-611

Tornqvist L, Vartia P, Vartia YO. How Should Relative Changes Be Measured. American Statistician, 1985; 39(1): 43-46

Uthman O, Aremu O. Comparison of physical activity level between overweight/obese and normal weight individuals: A systematic review. The Internet Journal of Nutrition and Wellness, 2007; 5(1)

Wiacek M, Hagner W, Hagner-Derengowska M, Bluj B, Czereba J, Drozd M, Zubrzycki IZ. Deterioration of basic coordinative parameters defines life quality of elderly. Arch Gerontol Geriatr, 2009; 49(2): 212-214

\section{Corresponding author:}

\section{Igor Z. Zubrzycki}

Jędrzej Śniadecki Academy of Physical Education and Sport ul. Kazimierza Górskiego 1, 80-336 Gdańsk, Poland

Email: igorzubrzycki@yahoo.com 